\title{
NEUTRON TEXTURE INVESTIGATIONS ON NATURAL MT. ISA CHALCOPYRITE ORE. PART I: PREFERRED ORIENTATION OF ONE AND THE SAME CHALCOPYRITE SAMPLE BEFORE AND AFTER EXPERIMENTAL DEFORMATION
}

\author{
E. M. JANSEN ${ }^{1}$, H. -G. BROKMEIER ${ }^{2}$ and H. SIEMES ${ }^{1}$ \\ ${ }^{1}$ Institut für Mineralogie und Lagerstättenlehre, RWTH Aachen, Wüllnerstr. 2, \\ D-52056 Aachen, Germany \\ ${ }^{2}$ Institut für Metallkunde und Metallphysik, TU Clausthal, Außenstelle GKSS \\ Forschungszentrum, Postfach 1160, D-21494 Geesthacht, Germany
}

(Received 10 September 1995)

\begin{abstract}
Natural chalcopyrite samples from Mt. Isa, Australia were axially shortened with a constant strain rate of $3 \cdot 10^{-5} \mathrm{sec}^{-1}$, at a constant confining pressure of $300(400) \mathrm{MPa}$ and at different temperatures. Neutron diffraction texture analyses were carried out before and after experimental deformation on one and the same sample. The preferred orientation of the experimentally undeformed samples consists of three main orientation components, which become weaker with deformation at temperatures up to $200^{\circ} \mathrm{C}$. One or two new components develop with the c-axes perpendicular to the principal strain direction. At a deformation temperature of $300^{\circ} \mathrm{C}$ two very different new components develop, the original components are completely dissolved.
\end{abstract}

KEY WORDS: Chalcopyrite, experimental deformation, temperature, neutron diffraction, preferred orientation, pole figure

\section{INTRODUCTION}

The tetragonal structure of chalcopyrite $\left(\mathrm{CuFeS}_{2}\right)$ is a derivative of the cubic sphalerite structure $(\mathrm{ZnS})$, where the $\mathrm{Cu}$ and $\mathrm{Fe}$ atoms alternately occupy the $\mathrm{Zn}$ positions along the c-direction. Thus, the unit cell is doubled in c-direction, the ratio $a_{0} / c_{o}$ being 1.97. Identical reflections in the cubic system (e.g. $(200)=(002))$ are partially overlapping double reflections for chalcopyrite (e.g. (200/004)). In X-ray texture goniometry only incomplete pole figures of the pseudocubic (112) and (220/204) reflections can be measured. After axial shortening at $25^{\circ} \mathrm{C}$ (Lang, 1968) to $450^{\circ} \mathrm{C}$ (Jansen et al., 1993) chalcopyrite shows a maximum of the (220/204) double reflection perpendicular to the principal strain direction. Lang interpreted the chalcopyrite preferred orientation as a (220/204) fiber texture similar to the (220) fiber texture of sphalerite (Siemes et al., 1994).

Chalcopyrite deformation experiments at temperatures up to $500^{\circ} \mathrm{C}$ have been performed by Atkinson (1974), Kelly and Clark (1975) and Roscoe (1975), but without accompanying texture analysis. 
A successful separation of the chalcopyrite double reflections was obtained by neutron diffraction. The measurements were carried out at the FRJ-2 reactor, KFA Jülich using a position sensitive detector (PSD) and a subsequent peak profile analysis (Jansen et al., 1991, 1993). Five samples from Mt. Isa axially shortened at temperatures of 25, $100,200,300$ and $400^{\circ} \mathrm{C}$ were investigated. The measured (112), (200), (004), (220), (204), (312), (116), (224), (400) and (008) pole figures were usable to evaluate the preferred orientation. The pole figures of the samples shortened at low temperatures showed four, at higher temperatures two main orientation components, but no fiber texture was detectable. The interpretation of this texture requires the knowledge of the texture of the undeformed material, but X-ray measured slices of the undeformed material didn't show a clear preferred orientation. Thus, a new testing series seemed to be necessary to study the bulk texture of the same sample before and after experimental deformation by neutron diffraction. As the FRJ-2 reactor in Jülich didn't operate during the last years the neutron measurements were performed at the FRG1 at Geesthacht, GKSS-Research Centre. But, as the instrument wasn't equipped with a PSD at that time, another method to separate the chalcopyrite double reflections has to be used.

\section{STARTING MATERIAL AND DEFORMATION EXPERIMENTS}

Cylindrical specimens of $15 \mathrm{~mm}$ diameter and $30 \mathrm{~mm}$ length were prepared from the Mt. Isa chalcopyrite ore, which had already been used for earlier deformation experiments (Jansen and Siemes, 1993; Jansen et al., 1993). The ore consists of $85 \%$ chalcopyrite, $3 \%$ pyrrhotite, $1 \%$ pyrite and $11 \%$ quartz and other minerals, the average grain diameter of chalcopyrite being $0.3 \mathrm{~mm}$. Eight samples were axially shortened at a constant confining pressure of $300 \mathrm{MPa}(400 \mathrm{MPa}$ for room temperature) and with a constant strain rate of about $3 \cdot 10^{-5} \mathrm{sec}^{-1}$. Two experiments at temperature of 25,100 , and $200^{\circ} \mathrm{C}$, and one experiment at 300 were performed, one experiment at $400^{\circ} \mathrm{C}$ failed after a few percent strain. Details of the experimental conditions are given in Table 1 .

\section{NEUTRON TEXTURE ANALYSIS}

The texture measurements were performed at TEX-2, the neutron texture diffractometer

Table 1 Deformation experiments

\begin{tabular}{lccccc}
\hline $\begin{array}{l}\text { Sample } \\
\text { No. }\end{array}$ & $\begin{array}{c}\text { Temperature } \\
\left({ }^{\circ} \mathrm{C}\right)\end{array}$ & $\begin{array}{c}\text { Strain rate } \\
\left(\mathrm{sec}^{-1}\right)\end{array}$ & $\begin{array}{c}\text { Total strain } \\
(\%)\end{array}$ & $\begin{array}{c}\text { Run } \\
\text { dur. }\end{array}$ & $\begin{array}{c}\Delta \sigma(\varepsilon=10 \%) \\
(M P a)\end{array}$ \\
\hline 1 CH8311 & 25 & $2.6 \cdot 10^{-5}$ & 16.14 & $2.0 \mathrm{~h}$ & 888 \\
$2 \mathrm{CH} 8307$ & 25 & $2.5 \cdot 10^{-5}$ & 17.26 & $2.1 \mathrm{~h}$ & 783 \\
$3 \mathrm{CH} 8318$ & 100 & $2.4 \cdot 10^{-5}$ & 9.54 & $1.4 \mathrm{~h}$ & $(807)$ \\
$4 \mathrm{CH} 8310$ & 100 & $2.6 \cdot 10^{-5}$ & 17.34 & $2.1 \mathrm{~h}$ & 748 \\
$5 \mathrm{CH} 8302$ & 200 & $2.7 \cdot 10^{-5}$ & 18.28 & $2.1 \mathrm{~h}$ & 524 \\
$6 \mathrm{CH} 8219$ & 200 & $2.8 \cdot 10^{-5}$ & 20.45 & $2.2 \mathrm{~h}$ & 488 \\
7 CH8320 & 300 & $2.7 \cdot 10^{-5}$ & 19.56 & $2.1 \mathrm{~h}$ & 335 \\
\hline
\end{tabular}


Table 2 Calculated positions and intensities of the important chalcopyrite reflections for a neutron beam of $0.134 \mathrm{~nm}$ wavelength using LAZY PULVERIX (Yvon et al., 1977).

\begin{tabular}{lcr}
\hline$(h k l)$ & 2Theta & $I(\%)$ \\
\hline$(101)$ & 16.31 & 1.5 \\
$(112)$ & 25.44 & 100.0 \\
$(200)$ & 29.31 & 15.5 \\
$(004)$ & 29.75 & 7.5 \\
$(220)$ & 41.93 & 31.5 \\
$(204)$ & 42.25 & 62.2 \\
\hline
\end{tabular}

at GKSS Research Center (Brokmeier, 1989). The structural data of chalcopyrite were used to calculate the theoretical 2-Theta positions of the reflections for a wavelength of $0.134 \mathrm{~nm}(\mathrm{Cu}(111)$ monochromator). Table 2 gives the first and strongest reflections of the spectrum. Only the weak (101) and the strong (112) reflections are measureable as single reflections. For testing purposes two different chalcopyrite sample cylinders were chosen, one experimentally undeformed and one experimentally shortened by $30 \%$ at $400^{\circ} \mathrm{C}$ (Jansen et al. 1993). Complete pole figures of the (101), (112) reflections and the (200/004), (220/204) double reflections were measured for both of the samples. The counting time for the (112) reflection was 2.5 hours, for the weaker reflections it was increased: 3.5 times for (200/004) and 7 times for (101). The (101) and (112) pole figures were also used to calculate orientation distribution functions (ODFs) by means of the iterative series expansion method using the positivity condition (Dahms and Bunge, 1989; Dahms, 1992). From the ODFs the (101) and (112) pole figures were recalculated, and showed a very good agreement with the measured ones. The ODFs were also used to calculate the (200), (004), (220) and (204) pole figures. The result of the pole figure calculation using only two sets of pole figures and only one with tetragonal information for the ODF calculation had to be verified. The calculated (200) and (004), as well as (220) and (204) pole figures were weighted with their theoretical intensities and added in order to obtain the superimposed sum pole figures $(200+004)$ and $(220+204)$. The sum pole figures were compared with the corresponding measured pole figures (200/004) and (220/204) of the overlapping reflections. Figure 1 shows that the agreement of the compared pole figures is very good for the undeformed sample CH8320 as well as for the deformed sample CH8410.

So the texture analysis procedure for all undeformed and afterwards deformed samples was the following: measuring the (101) and (112) pole figures, calculating the ODF, recalculating the (101) and (112) pole figures and calculating the (200), (004), (220) and (204) pole figures from the ODF.

\section{PREFERRED ORIENTATION BEFORE EXPERIMENTAL DEFORMATION}

Before using the neutron diffraction technique for texture analysis, slices from bottom and top of the undeformed sample cylinders were measured by $\mathrm{X}$-ray diffraction. Examples of incomplete X-ray measured (112) and (220/204) pole figures in Figure 2 show, that it was not possible to identify a pervading preferred orientation for the 

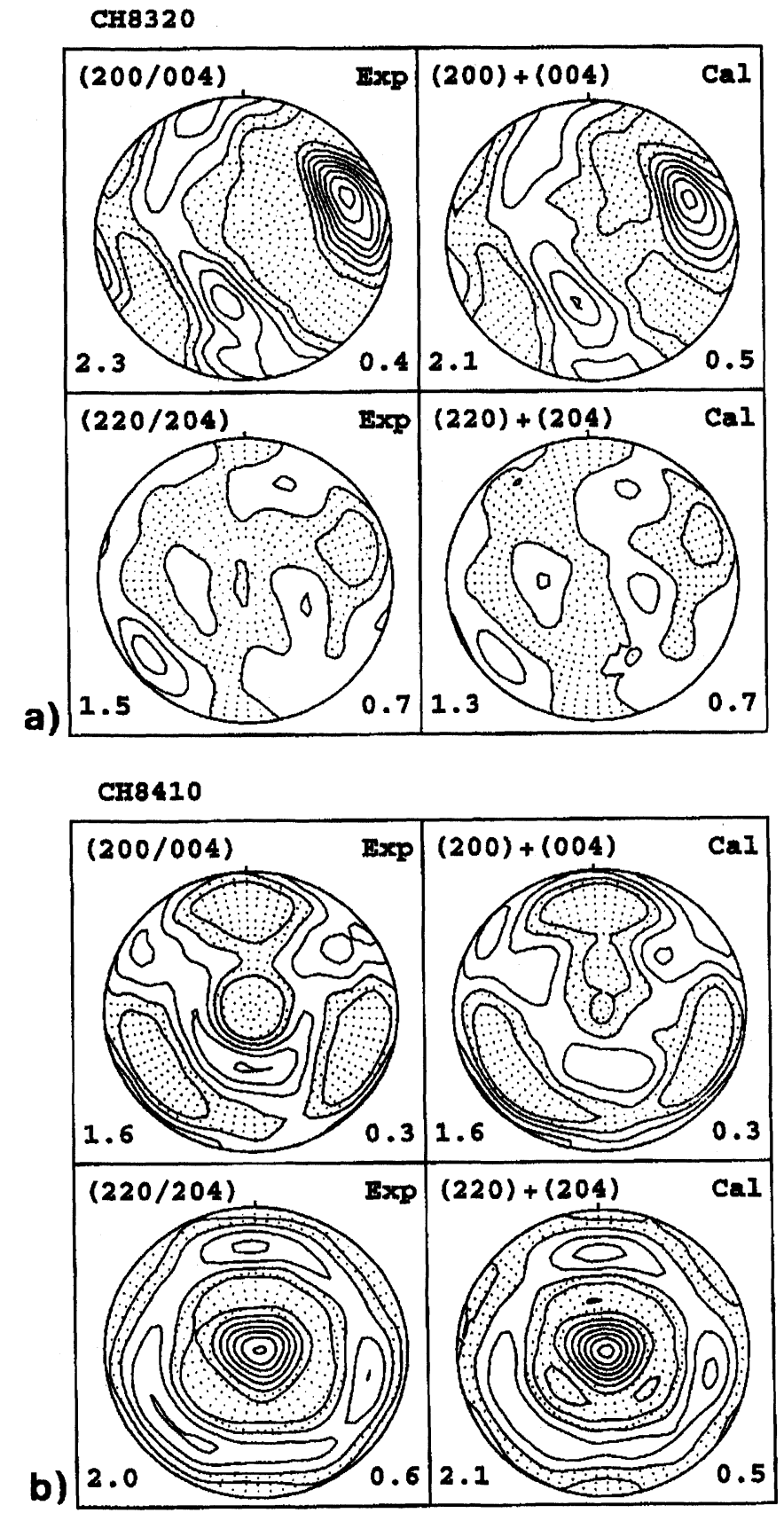

Figure 1 Neutron measured (200/004) and (220/204) pole figures compared to calculated (200) $+(004)$ and $(220)+(204)$ sum pole figures, a) sample CH8320 (undeformed), b) sample CH8410 (experimentally deformed); equal area projection, dotted areas: intensities below 1, contour interval: 0.2 , bottom left: maximum, bottom right: minimum intensity. 

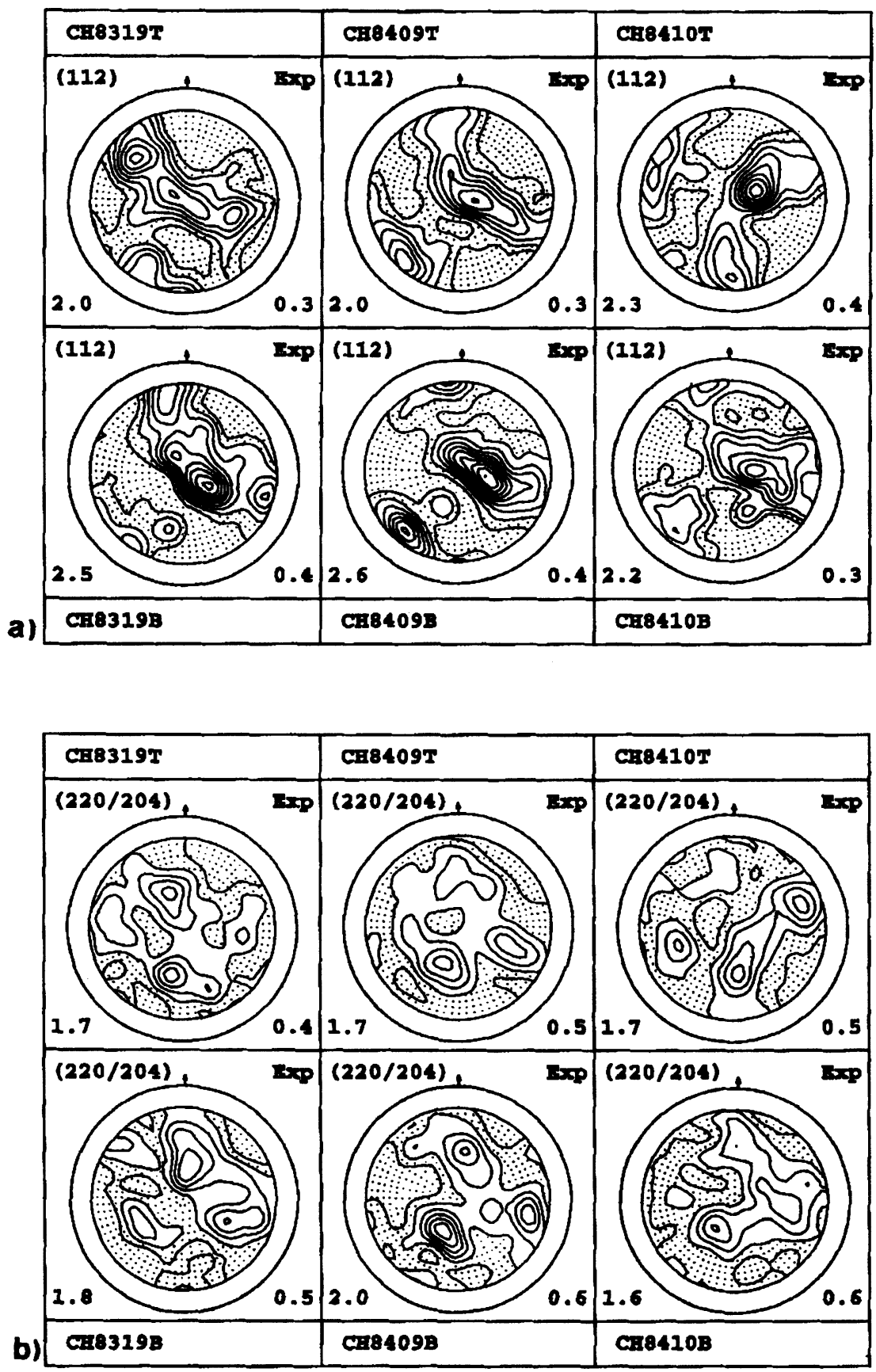

Figure 2 X-ray measured incomplete a) (112) and b) (220/204) pole figures from top (T) and bottom (B) slices of undeformed chalcopyrite sample cylinders; equal area projection, dotted areas: intensities below 1 , contour interval: 0.2 , bottom left: maximum, bottom right: minimum intensity. 
Mt. Isa ore handspecimen. However, the neutron texture analysis gives evidence of a distinct preferred orientation of the ore. The neutron measured complete (101), (112) and calculated (004) pole figures of the eight investigated samples are given in Figure 3. Comparing the measured (101) and (112) pole figures (EXP) with the recalculated ones (REC) in Figures 4-7, a very good agreement is demonstrated. The (101) pole figures, although essential for the calculation, cannot give much visible information. The pseudocubic (112) pole figures show a quasi single crystal orientation, where the maxima are nearly spread to small circle distributions. More information is visible in the (004) pole figures, where similar maxima positions are marked with the same symbols 1,2 and 3 . The (004) pole figures of all samples show three main orientation components slightly different in position and intensity of the maxima, but very similar.

This is also proofed for the other pole figures by using the component fit program of Helming and Eschner (1990). Component 1 is the strongest for six of the eight samples.

\section{PREFERRED ORIENTATION CHANGES AFTER DEFORMATION}

After deformation at 25,100 and $200^{\circ} \mathrm{C}$ (Figures 4-6a,b) the original three orientation components are still existing, but of weaker intensities and also slightly shifted their positions. From parts of the original components 3 and 1 two new components $A$ and $\mathrm{B}$ have developed with the c-axes perpendicular to the principal strain direction. These components are responsible for the new central maximum of (220) for each of the six samples. For five of the six samples component A, near the samples' north direction, is stronger. Only sample CH8307 (Figure 4b) shows a more pronounced component B. Also central maxima of (101) and (204) are found after deformation at 25 and $100^{\circ} \mathrm{C}$, which are produced by the relics of all three original orientation components. After deformation at $200^{\circ} \mathrm{C}$ the fraction of the original components is more reduced, there is no central (101) maximum detectable, but still a (204) maximum (Figure 6a, b). After deformation at $300^{\circ} \mathrm{C}$ the original components disappeared (Figure 7). Besides the new component $A$, which developed from the original component 3, another new component $C$ developed, probably from component 1,2 and 3, with (004) about 45 degrees off the center of the projection. In contrast to the other samples, this new component $\mathrm{C}$ produces the central (204) maximum for this sample, and a minimum in the center of (101). The pole figures of this sample at least give an intimation of a fiber texture. The differences in preferred orientation between a deformation temperature of $300^{\circ} \mathrm{C}$ and lower temperatures point to a change in deformation mechanisms.

\section{CONCLUSIONS}

For the special problem of the chalcopyrite preferred orientation the superiority of the neutron beam over the X-rays in texture analysis is evident. As the total specimen volume is measured by neutron diffraction, the statistics of the weak tetragonal (101) reflection of chalcopyrite is sufficient for the ODF calculation. And as the same specimen volume can be measured before and after experimental deformation, real differences in preferred orientation induced by the deformation processes are observable.

If the original texture of a material in axial shortening experiments is a random 


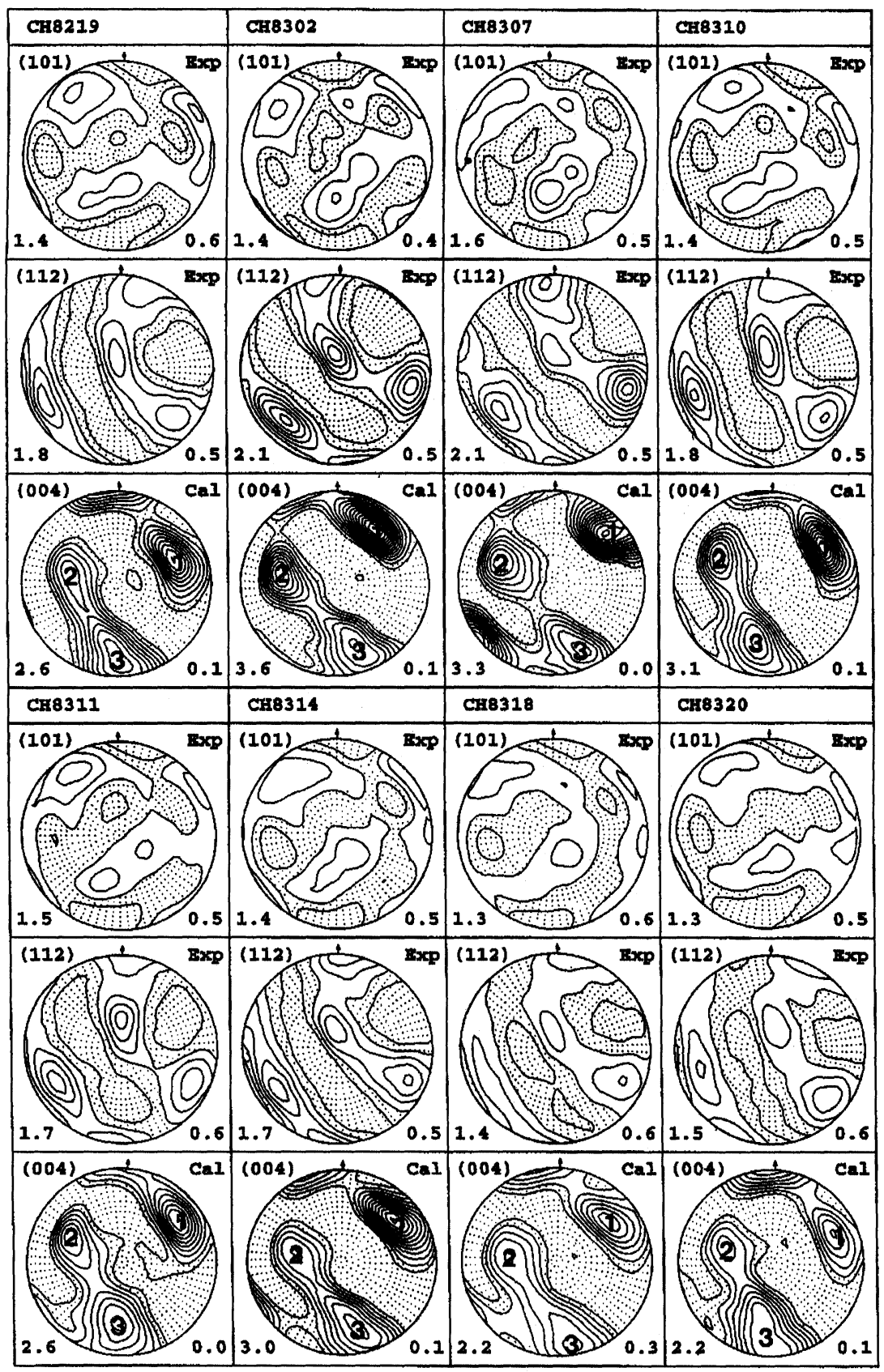

Figure 3 Neutron measured complete (101) and (112), and ODF calculated (004) pole figures of the 8 investigated chalcopyrite samples; equal area projection, dotted areas: intensities below 1 , contour interval: 0.2 , bottom left: maximum, bottom right: minimum intensity. 

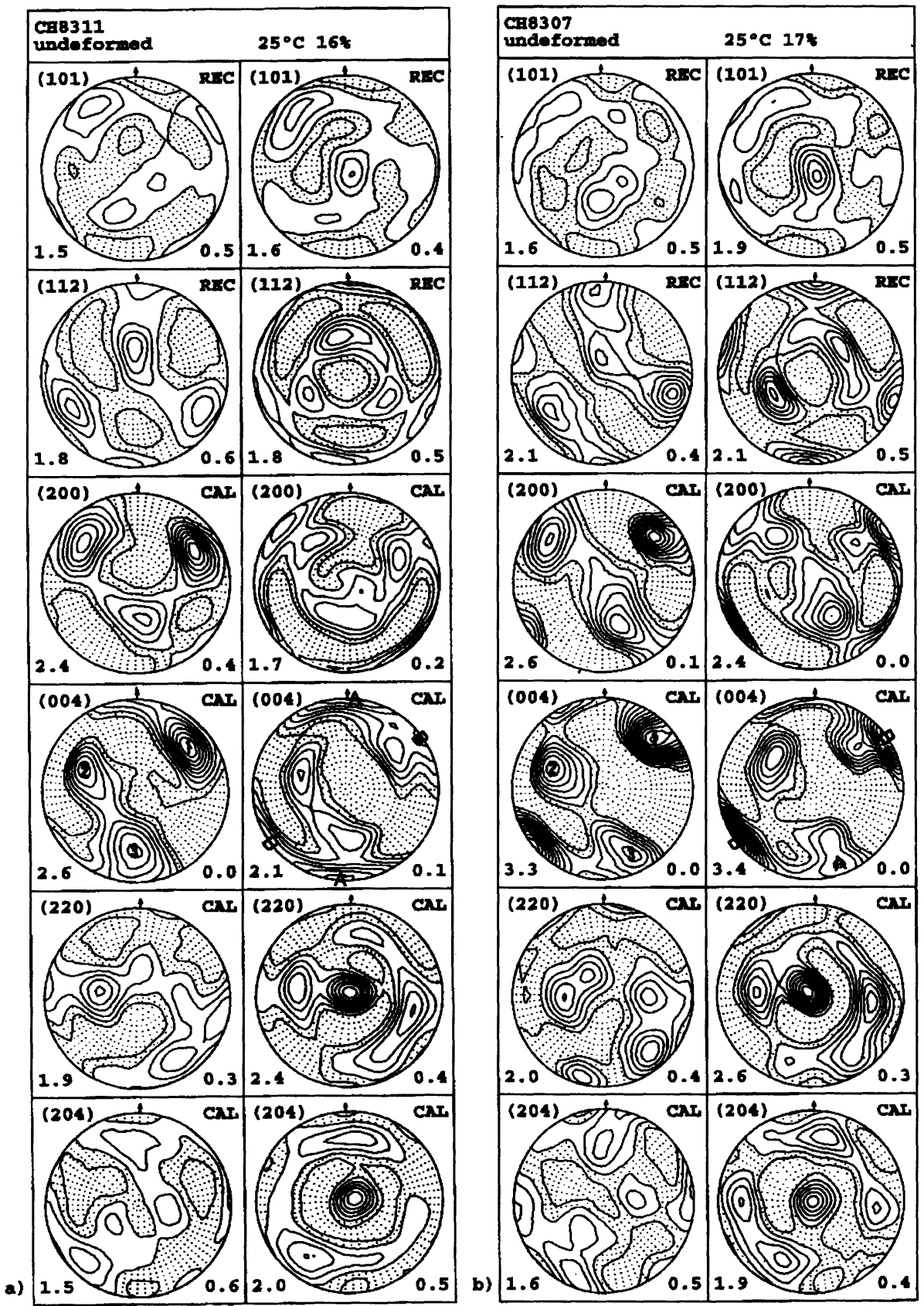

Figure 4 ODF recalculated complete (101) and (112), and calculated (200), (004), (220) and (204) pole figures of sample a) $\mathrm{CH} 8311$ and b) $\mathrm{CH} 8307$ before and after experimental deformation at $25^{\circ} \mathrm{C}$; equal area projection, dotted areas: intensities below 1 , contour interval: 0.2 , bottom left: maximum, bottom right: minimum intensity. 

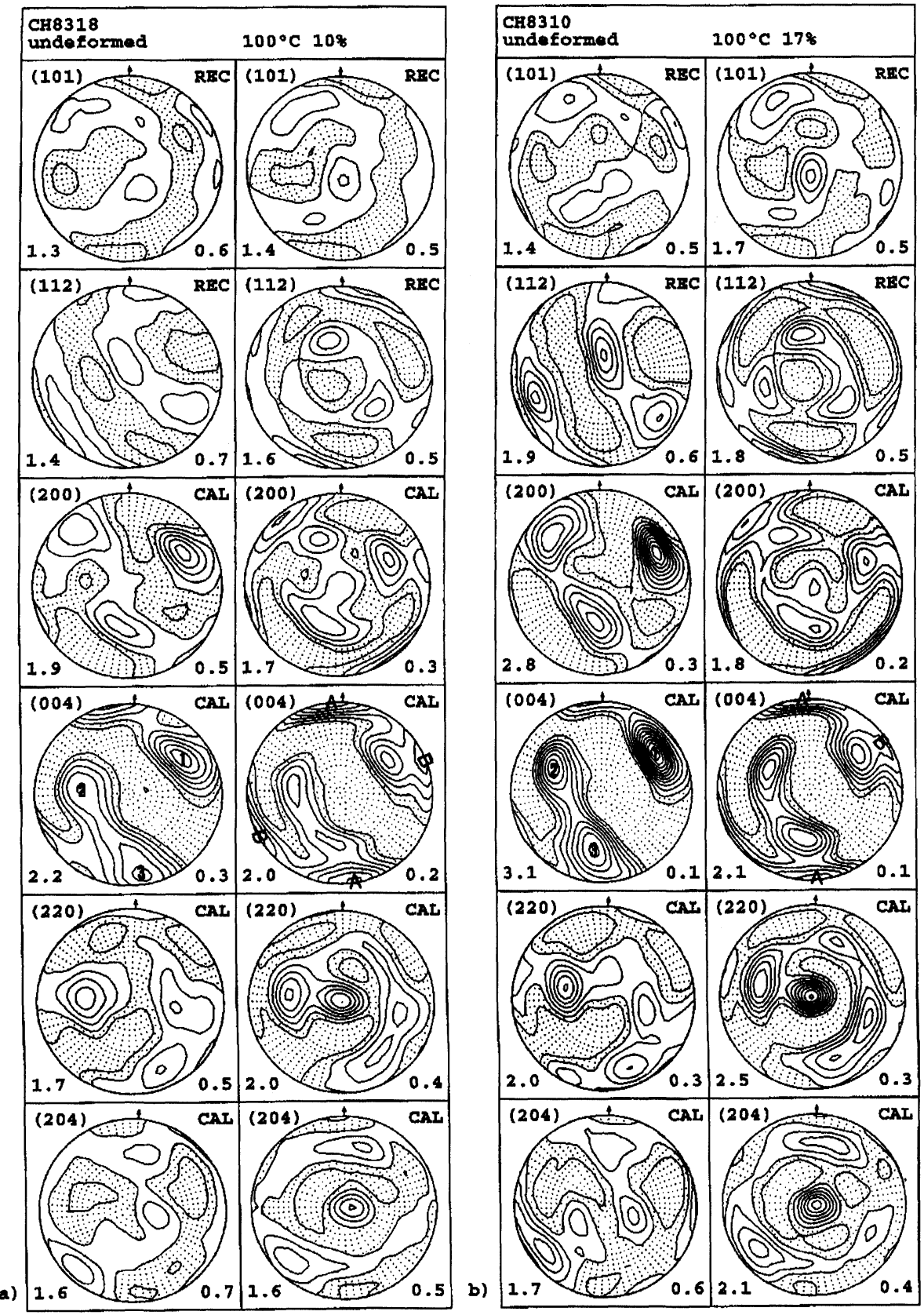

Figure 5 ODF recalculated complete (101) and (112), and calculated (200), (004), (220) and (204) pole figures of sample a) $\mathrm{CH} 8318$ and b) $\mathrm{CH} 8310$ before and after experimental deformation at $100^{\circ} \mathrm{C}$; equal area projection, dotted areas: intensities below 1, contour interval: 0.2 , bottom left: maximum, bottom right: minimum intensity. 

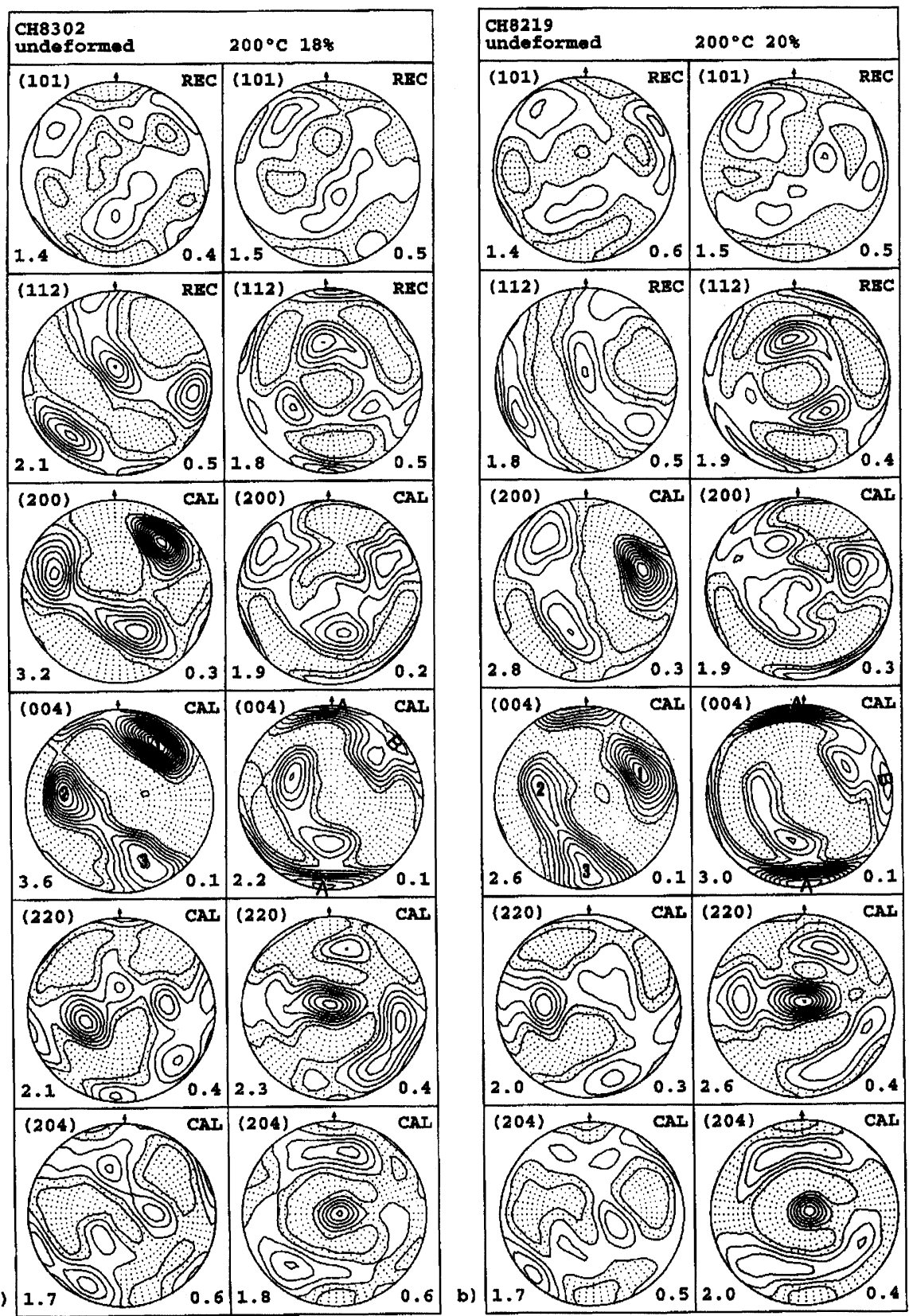

Figure 6 ODF recalculated complete (101) and (112), and calculated (200), (004), (220) and (204) pole figures of sample a) $\mathrm{CH} 8302$ and b) $\mathrm{CH} 8219$ before and after experimental deformation at $200^{\circ} \mathrm{C}$; equal area projection, dotted areas: intensities below 1, contour interval: 0.2 , bottom left: maximum intensity, bottom right: minimum intensity. 


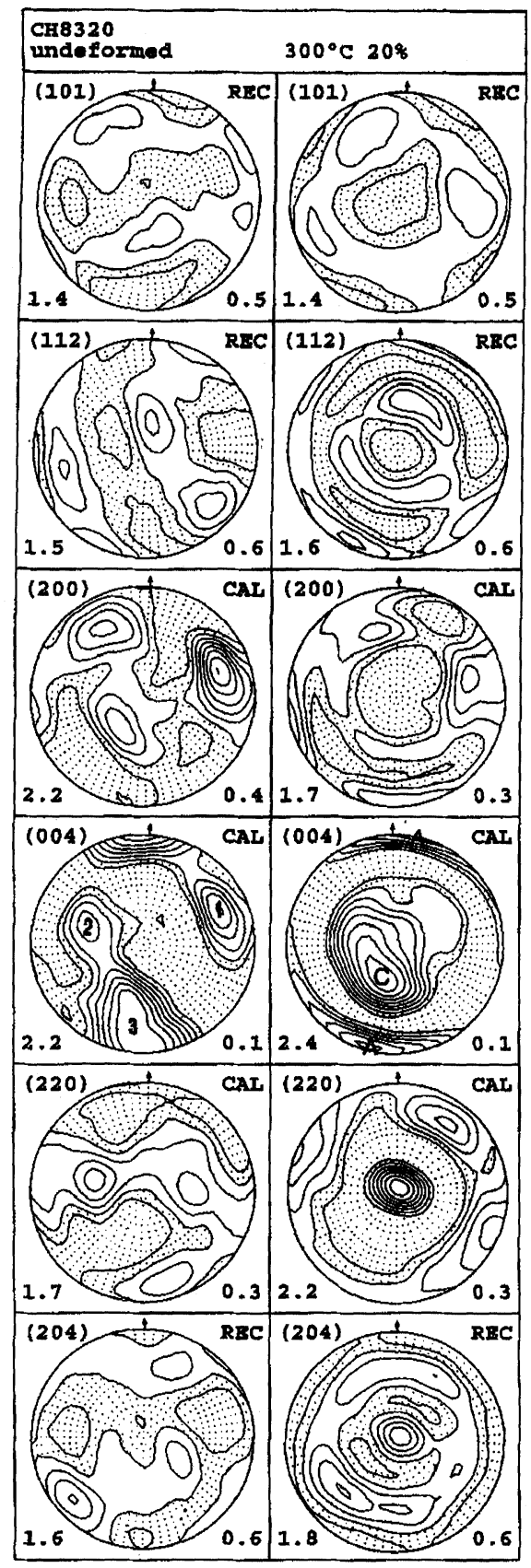

Figure 7 ODF recalculated complete (101) and (112), and calculated (200), (004), (220) and (204) pole figures of sample $\mathrm{CH} 8320$ before and after experimental deformation at $300^{\circ} \mathrm{C}$; equal area projection, dotted areas: intensities below 1, contour interval: 0.2 , bottom left: maximum intensity, bottom right: minimum intensity. 
distribution, the development of an axial symmetric preferred orientation, a fiber texture, will start at once and will be visible after a few percent strain. A resulting fiber texture was not reached for the Mt. Isa chalcopyrite ore under the applied experimental conditions. In this case a detailed knowledge of the original preferred orientation, which is responsible for this effect, is of great importance. New orientation components can only develop from the original ones, and the deformation mechanisms strongly depend on the orientation of the crystallites to the strain direction.

The combination of four main orientation components, after low temperature deformation, and of two components, after high temperature deformation, of earlier neutron texture investigations on Mt. Isa chalcopyrite (Jansen et al., 1993), can now be explained in the same way as the components in this study. Two different new components developed after deformation at high temperatures, and at lower temperatures one stronger new component besides the relics of the three original components are found.

A change in deformation mechanisms, which is reported for single crystals to occur between $200^{\circ} \mathrm{C}$ and $400^{\circ} \mathrm{C}$ (Hennig-Michaeli and Couderc, 1989), is confirmed in the present study to take place between $200^{\circ} \mathrm{C}$ and $300^{\circ} \mathrm{C}$.

The results of the present study, particularly the knowledge of the original preferred orientation of the Mt. Isa material, lead to the conclusion, that further neutron diffraction texture analyses on the complete extensive series of earlier deformed Mt. Isa chalcopyrite samples (Jansen et al. 1993) can give more information about chalcopyrite deformation behaviour (Part II of this contribution, Jansen et al., 1995).

\section{Acknowledgements}

The authors wish to thank W. Murach for technical assistance at the TEX-2. B. Eisenlohr gratefully supplied the chalcopyrite ore from Mt. Isa, Australia. EMJ was funded by the Deutsche Forschungsgemeinschaft (Bonn) and HGB by the Bundesministerium für Forschung und Technologie (03BU3CLA F.4-K19).

\section{References}

Atkinson, B. K. (1974). Experimental deformation of polycrystalline galena, chalcopyrite and pyrrhotite. Inst. Mining Metallurgy Trans., 83, B19-B28.

Brokmeier, H. -G. (1989). Neutron Diffraction Texture Analysis of Multi-Phase Systems. Textures and Microstructures, 10, 325-346.

Dahms, M. (1992). The Iterative Series Expansion Method for Quantitative Texture Analysis - Part II: Applications, J. Appl. Cryst., 25, 258-267.

Dahms, M. and Bunge, H. -J. (1989). The Iterative Series Expansion Method for Quantitative Texture Analysis I. General Outline. J. Appl. Cryst., 22, 439-447.

Helming, K. and Eschner, T. (1990). A new approach to texture analysis of multiphase materials using a texture component model. Cryst. Res. Technol., 25, K203-208.

Hennig-Michaeli, C. and Couderc, J. J. (1989). TEM study of dislocation reactions in experimentally deformed chalcopyrite single crystals in: Deformation processes in minerals, ceramics and rocks, eds. Barber, D. J. and Meredith, P. G., Unwin Hyman, London, 391-414.

Jansen, E. M., Merz, P., Siemes and H., Will, G. (1991). Interpretation of preferred orientation in naturally and experimentally deformed chalcopyrite ores by neutron diffraction texture analysis. Textures and Microstructures, 14-18, 431-436 (Special Issue: Ninth Int. Conf. Text. Mat. (Icotom 9), Avignon 1990, Eds. Esling, C. and Penelle, R.).

Jansen, E. M. and Siemes, H. (1993). Phase reaction between chalcopyrite and pyrrhotite during axial compression experiments at $400^{\circ}$ and $450^{\circ} \mathrm{C}, 300 \mathrm{MPa}$ confining pressure and different strain rates. N. Jb. Miner. Mh., 7, 325-336.

Jansen, E. M., Siemes, H., Merz, P., H., Schäfer, W., Will, G. and Dahms, M. (1993). Preferred 
orientation of experimentally deformed Mt Isa chalcopyrite ore. Miner. Mag., 57, 45-53.

Jansen, E. M., Brokmeier, H. -G. and Siemes, H. (1995). Neutron texture investigations on natural Mt. Isa chalcopyrite ore. Part II: Preferred orientation of chalcopyrite after different experimental deformation conditions. Textures and Microstructures, following volume.

Kelly, W. C. and Clark, B. R. (1975). Sulfide deformation studies III. Experimental deformation of chalcopyrite to 2000 bars and $500^{\circ} \mathrm{C}$. Econ. Geol., 70, 431-453

Lang, H. (1968). Stauchversuche mit polykristallinen Kupferkiesen und deren Ergebnisse unter Berücksichtigung der Gefügeregelung. Dissertation RWTH Aachen, 131 p.

Roscoe, W. E. (1975). Experimental deformation of natural chalcopyrite at temperatures up to $300^{\circ} \mathrm{C}$ over the strain rate range $10^{-2}$ to $10^{-6} \mathrm{sec}^{-1}$. Econ. Geol., 70, 454-472

Siemes, H., Jansen, E. M. and Niederschlag E. (1994) Crystallographic preferred orientations of experimentally deformed sulfide ores in: Textures of geological materials (Bunge, H. J., Siegesmund, S., Skrotzki, W. and Weber, K. eds.), DGM Informationsgesellschaft, Oberursel, 231-250

Yvon, K., Jeitschko, W. and Parthe, E. (1977). LAZY PULVERIX, a computer program for calculating $\mathrm{X}$-ray and neutron diffraction powder patterns. J. Appl. Cryst., 10, 73-74. 